\title{
ANALISIS PENGGUNAAN MICROPILE UNTUK MEMINIMALKAN HEAVING PADA TANAH EKSPANSIF DI JAWA BARAT
}

\author{
Adianto C. Wijaya ${ }^{1}$ dan Alfred J. Susilo ${ }^{2}$ \\ ${ }^{1}$ Program Studi Sarjana Teknik Sipil, Universitas Tarumanagara, Jl. Letjen S. Parman No.1 Jakarta \\ Email: acw1610@gmail.com \\ ${ }^{2}$ Program Studi Sarjana Teknik Sipil, Universitas Tarumanagara, Jl. Letjen S. Parman No.1 Jakarta \\ Email: alfredsusilo@gmail.com
}

\begin{abstract}
ABSTRAK
Heaving pada tanah ekspansif merupakan salah satu permasalahan yang ada pada dunia konstruksi. Salah satu penyebab utamanya adalah adanya kandungan montmorillonite yang terkandung pada tanah ekspansif. Butiran lempung montmorillonite pada tanah ekspansif tersebut akan mengembang karena ikatan kimia antar partikel dipengaruhi oleh terjadinya peningkatan kadar air. Pencegahan yang tepat dan efektif diperlukan untuk mengatasi masalah terkait heaving pada yang terjadi pada tanah ekspansif. Micropile merupakan salah satu metode untuk meminimalkan heaving yang terjadi pada tanah ekspansif karena kemudahan ketika pelaksanaan di lapangan, ukuran micropile yang kecil, dan biaya yang relatif murah. Kapasitas micropile yang berguna untuk mengatasi tanah ekspansif yakni sifat kembang susut tanah ekspansif adalah kapasitas tarik micropile. Pada analisis ini, metode pendekatan empiris yang digunakan untuk menganalisis tekanan pengembangan yang terjadi pada tanah ekspansif adalah metode yang dirumuskan oleh Kormonik, David, Nayak, dan Christensen. Disamping itu, analisis ini menggunakan metode pendekatan empiris untuk mengestimasi kenaikan tanah ketika terjadinya heaving pada tanah ekspansif yaitu penggunaan metode Van der Merwe. Hasil pengolahan data tanah ekspansif dan analisis data tanah ekspansif yang telah dilakukan, nantinya akan dilakukan perbandingan dengan kapasitas micropile untuk meminimalisir heaving yang terjadi akibat tanah ekspansif. Analisis ini menghasilkan efektivitas micropile untuk meminimalkan heaving yang terjadi akibat dari sifat tanah ekspansif.
\end{abstract}

Kata kunci: heaving, micropile, tanah ekspansif, montmorillonite, pengembangan

\section{PENDAHULUAN}

\section{Latar belakang}

Tanah merupakan salah satu bagian penting dalam pelaksanaan konstruksi karena tanah merupakan dasar bagi suatu bangunan yang berdiri di atasnya. Kondisi tanah sangat berpengaruh terhadap bangunan di atasnya sehingga sangat perlu untuk dilakukan penelitian untuk mengetahui kondis tanah.

Menurut Putra (2017) tanah terdiri dari berbagai macam partikel diantaranya batuan ukuran besar, kerikil, pasir, lanau, lempung dan koloid. Lempung terdiri dari berbagai mineral dan mika. Terdapat tiga jenis mineral lempung yang sudah dikenal yaitu montmorillonite, kaolinite, dan illite. Salah satu mineral yang bisa mengakibatkan pengembangan yaitu mineral montmorillonite sehingga termasuk dalam kategori ekspansif. Mineral kaolinite tidak termasuk dalam kategori ekspansif. Mineral illite termasuk dalam kategori ekspansif, akan tetapi tidak mengakibatkan banyak masalah (Hardiyatmo, 2014).

Tanah ekspansif adalah tanah yang mudah mengalami kembang susut ketika terjadi perubahan kadar air. Salah satu penyebab adanya fenomena kembang susut tersebut adalah perubahan ikatan antar partikel pada mineral montmorillonite akibat dari perubahan kadar air. Tanah ekspansif akan mengalami penyusutan bila kadar air menurun dan akan mengalami pengembangan bila kadar air meningkat sehingga diperlukan identifikasi untuk mendalami sifat dan karakteristik tanah ekspansif terutama untuk mengatasi kerugian yang ditimbulkan.

Ada berbagai solusi untuk mengatasi tanah ekspansif diantaranya penggantian material, membran horisontal, membran vertikal, pemberian prabeban (surcharge load), dan stabilisasi dengan kapur atau semen. Akan tetapi berbagai solusi tersebut membutuhkan metode yang cukup rumit sehingga berakibat pada mahalnya biaya yang dikeluarkan untuk menjalankan solusi tersebut.

Salah satu solusi yang murah dan mudah adalah penggunaan micropile untuk meminimalkan fenomena heaving yang terjadi pada tanah ekspansif. Proses konstruksi micropile memiliki kelebihan yaitu menciptakan 
sedikit gangguan di semua jenis dan kondisi tanah, menghasilkan sedikit suara dan getaran, dapat dilakukan di ruangan yang sempit.

\section{Batasan masalah}

Dalam penelitian ini, batasan-batasan yang digunakan sebagai berikut:

1. Aturan perhitungan mengacu pada Micropile Design and Construction (Reference Manual for NHI Course 132078).

2. Analisis tanah di daerah Karawang dan Cikarang.

3. Hanya membahas heaving pada tanah ekspansif.

4. Tidak menganalisis penyusutan tanah ekspansif.

5. Beban yang diperhitungkan hanya beban tarik dan horisontal (pengembangan tanah ekspansif).

6. Tidak memperhitungkan negative skin effect/downdrag.

7. Tidak menganalisa efek korosi pada micropile.

8. Tipe grouting yang dipakai adalah tipe gravity.

9. Tidak memperhitungkan adanya beban gempa.

10. Tidak memperhitungkan defleksi micropile.

11. Tidak memperhitungkan penurunan tanah.

\section{Rumusan masalah}

Rumusan masalah yang akan dibahas pada penelitian ini adalah efektivitas micropile untuk meminimalkan heaving pada tanah ekspansif di daerah Jawa Barat

\section{Tujuan penelitian}

Beberapa tujuan dari penelitian ini adalah:

1. Untuk mengetahui seberapa besar heaving yang terjadi pada tanah ekspansif

2. Untuk mengetahui efektivitas micropile untuk meminimalisir heaving pada tanah ekspansif di daerah Kawasan Jawa Barat 1 dan Kawasan Jawa Barat 2.

\section{Manfaat penelitian}

Penelitian ini diharapkan dapat memberikan manfaat sebagai berikut:

1. Berguna sebagai sumbangan pemikirian mengenai salah satu opsi dalam memperbaiki tanah ekspansif

2. Berguna sebagai salah satu referensi bagi para pembaca khususnya para mahasiswa dan masyarakat yang akan melakukan penelitan mengenai tanah yang berhubungan dengan teknik sipil

\section{Tanah Ekspansif}

Menurut Bella dkk. (2015), Tanah ekspansif adalah jenis tanah berbutir halus yang terbentuk dari mineral-mineral ekspansif sehingga mengakibatkan lempung ini memiliki potensi kembang susut tinggi apabila terjadi perubahan kadar air.

Mineral lempung tergantung pada batuan asal, topografi, iklim, waktu lamanya pelapukan, dan tumbuhan yang ada didekatnya. Menurut Hardiyatmo (2014) mineral yang ada pada lempung adalah mineral kristalin. Mineral kristalin tersebut memiliki bentuk seperti lembaran-lembaran dan memiliki kemampuan dalam mengembangkan kohesi dan plastisitas. Kohesi tersebut disebabkan oleh adanya gaya tarik-menarik dan ikatan antar lembaran-lembaran dengan air. Komposisi mineral merupakan sifat yang sangat penting dari tanah-tanah dengan komposisi butir halus. Terdapat tiga susunan mineral penyusun lempung yaitu kaolinite, illite, dan montmorillonite.

Kaolinite merupakan mineral yang tersusun dari satu lembar silika tetrahedral dan satu lembar aluminium oktahedral. Kedua lembaran tersebut terikat secara bersama sedemikian rupa dari ujung lembaran silika dan satu lapisan lembaran oktahedral membentuk suatu lapisan tunggal. Oleh karena adanya ikatan hidrogen diantara lembaran silika dan aluminium, maka kaolinite bersifat tidak ekspansif.

Illite merupakan mineral yang tersusun dari satu lembar aluminium oktahedra yang kemudian terikat diantara dua lembar silika tetrahedra. Lembaran-lembaran tersebut terikat secara bersama oleh ikatan lemah ion kalium. Ikatan lemah ion kalium memiliki kekuatan ikatan yang lebih lemah dari ikatan hidrogen. Akan tetapi, ikatan tersebut lebih 
kuat dari ikatan ion yang membentuk mineral montmorillonite. Susunan mineral illite memiliki sifat yang tidak mudah atau sedikit mengembang jika ada air diantara lembaran-lembarannya.

Montmorillonite merupakan mineral yang tersusun dari dua lembar silika tetrahedra dan satu lembar aluminium oktahedra. Antar lembaran silika diikat oleh ikatan Van der Waals yang lemah sehingga menyebabkan air dan ionion yang berpindah-pindah dapat dengan mudah masuk dan memisahkan lapisannya. Oleh karena itu, montmorillonite pada waktu tertentu sangat mudah mengembang oleh adanya tambahan kadar air.

\section{Metode Empiris untuk Memprediksi Tekanan Pengembangan}

Parameter tanah berupa nilai kadar air natural, massa jenis kering air, batas cair, indeks plastisitas, persen butiran lempung, dan nilai aktivitas bisa dipakai memprediksikan potensi pengembangan dan tekanan pengembangan secara empiris.

Kormonik dan David (Tu, 2015) merumuskan tekanan pengembangan dengan menggunakan persamaan

$$
\log P_{s}\left(\mathrm{~kg} / \mathrm{cm}^{2}\right)=-2.132+0.0208 L L+0.000665 \gamma_{d r y}-0.0269 \omega_{n}
$$

Nayak dan Christensen (Tu, 2015) merumuskan tekanan pengembangan dengan menggunakan persamaan

$$
P_{s}(p s i)=3.58 \times 10^{-2} x P I^{1.12} x\left[\frac{c}{\omega_{n}}\right]^{2}+3.8
$$

dengan $\mathrm{P}_{\mathrm{s}}=$ tekanan pengembangan, $\mathrm{LL}=$ batas cair $(\%), \gamma_{\text {dry }}=$ massa jenis kering air $\left(\mathrm{kg} / \mathrm{cm}^{3}\right), \omega_{\mathrm{n}}=$ nilai kadar air alami (\%), PI = indeks plastisitas (\%), c = fraksi ukuran lempung diameter butiran < $0.002 \mathrm{~mm}(\%)$

\section{Penentuan Kenaikan Tanah Berdasarkan Metode Van der Merwe}

Van der Merwe (Hardiyatmo, 2014) mengembangkan hubungan antara indeks plastisitas (PI), persen fraksi diameter butiran lempung $<0.002 \mathrm{~mm}$, dan tekanan vertikal untuk mengestimasi besarnya kenaikan pada tanah dengan menggunakan persamaan

$$
\begin{gathered}
\Delta H=\sum_{i=1}^{n} F_{i} x P E_{i} \\
F_{i}=10^{B} \\
B=\frac{-d}{20}
\end{gathered}
$$

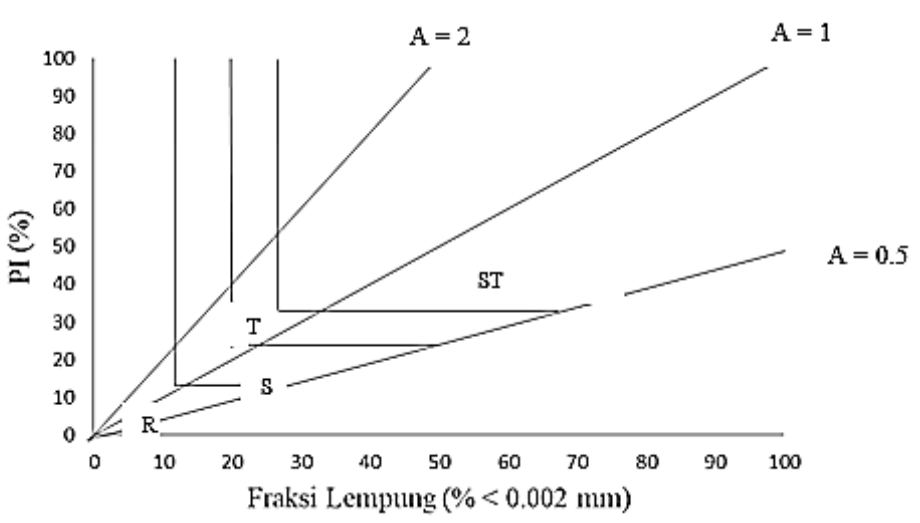

Gambar 1. Grafik Kategori Derajat Ekspansi

Tabel 1. Nilai PE (Hardiyatmo, 2014)

\begin{tabular}{cc}
\hline Derajat Ekspansi & $\mathrm{PE}(\mathrm{in} / \mathrm{ft})$ \\
\hline Rendah & 0 \\
\hline Sedang & 0.25 \\
\hline Tinggi & 0.5 \\
\hline Sangat Tinggi & 1 \\
\hline
\end{tabular}


dengan $\Delta \mathrm{H}=$ kenaikan tanah total (inch), $\mathrm{d}=$ kedalaman lapisam tanah dalam penambahan tiap-tiap $1 \mathrm{ft}$ sampai lapisan yang ditinjau, $\mathrm{F}_{\mathrm{i}}$ = faktor reduksi untuk tekanan vertikal, dan $\mathrm{PE}_{\mathrm{i}}=$ potensi ekspansif tiap kedalaman in/ft.

\section{Kapasitas Dukung Micropile}

Analisis kapasitas dukung micropile menggunakan persamaan yang dirumuskan oleh Federal Highway Administration (FHWA). Kapasitas dukung micropile terbagi atas allowable compression load for cased length, allowable tension load for cased length, allowable compression load for uncased length, allowable tension load for uncased length.

Allowable compression load for cased length menggunakan persamaan :

$$
P_{c-\text { allowable }}=\left[0.4 f_{c-\text { grout }}^{\prime} x A_{\text {grout }}+0.47 F_{y-\text { steel }}\left(A_{\text {bar }}+A_{\text {casing }}\right)\right]
$$

Allowable tension load for cased length menggunakan persamaan :

$$
P_{\text {t-allowable }}=\left[0.55 F_{y-\text { steel }} x\left(A_{\text {bar }}+A_{\text {casing }}\right)\right]
$$

Allowable compression load for uncased length menggunakan persamaan :

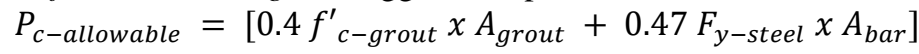

Allowable tension load for uncased length menggunakan persamaan :

$$
P_{\text {t-allowable }}=\left[0.55 F_{y-\text { steel }} x\left(A_{\text {bar }}+A_{\text {casing }}\right)\right]
$$

dengan $P_{c \text {-allowable }}=$ gaya tekan yang diijinkan $(\mathrm{N}), f_{c \text {-grout }}^{\prime}=$ kuat tekan beton (MPa), $A_{\text {grout }}=$ luas area beton $\left(\mathrm{m}^{2}\right)$, $F_{y \text {-steel }}=$ tegangan leleh baja $(\mathrm{MPa}), A_{\text {bar }}=$ luas area tulangan $\left(\mathrm{m}^{2}\right)$, dan $A_{\text {casing }}=$ Luas area casing $\left(\mathrm{m}^{2}\right)$.

\section{METODOLOGI PENELITIAN}

\section{Metode pengumpulan data}

Metode yang digunakan untuk pengumpulan data penelitian ini adalah teknik dokumentasi yaitu pengumpulan data dari proyek. Pada penelitian ini, data tanah yang dianalisis berlokasi pada daerah Karawang (Kawasan Jawa Barat 1) dan Cikarang (Kawasan Jawa Barat 2), Jawa Barat. Data tanah berupa boring log sedalam 30 meter dan hasil tes laboratorium.

\section{Metode analisis data}

Sebelum dilakukannya analisis, dilakukan studi literatur dengan mencari dasar-dasar teori dan sumber data seperti jurnal, buku referensi untuk mendapatkan rumus-rumus dalam menghitung daya dukung micropile dan besarnya tekanan pengembangan. Metode analisis yang digunakan untuk menghitung kapasitas dukung micropile yaitu menggunakan perhitungan manual yang mengacu pada FHWA. Metode analisis yang digunakan untuk menghitung besarnya tekanan pengembangan yaitu menggunakan perhitungan manual yang mengacu pada rumus Christensen, David, Kormonik, dan Nayak. Analisis akan dilakukan pada kondisi tanpa adanya micropile untuk mencari besarnya tekanan pengembangan yang terjadi dan kebutuhan micropile berdasarkan tekanan pengembangan yang terjadi.

\section{ANALISIS DAN PEMBAHASAN}

\section{Tekanan Pengembangan}

Berdasarkan data analisis laboratorium, lapangan dan hasil korelasi, dapat dianalisis untuk mendapatkan besarnya tekanan pengembangan yang terjadi. Berikut merupakan kesimpulan tekanan pengembangan dari Kawasan Jawa Barat 1 dan Kawasan Jawa Barat 2 tersaji dalam tabel 1,2,3, dan 4. 
Tabel 1. Parameter tanah Kawasan Jawa Barat 1

\begin{tabular}{cccccccc}
\hline Bor No. & Sample No. & $\begin{array}{c}\text { Sample Depth } \\
(\mathrm{m})\end{array}$ & $\begin{array}{c}\text { Dry Density } \\
\left(\mathrm{gr} / \mathrm{cm}^{3}\right)\end{array}$ & LL (\%) & PI (\%) & $\begin{array}{c}\text { \% finer } \\
<0.002 \\
\mathrm{~mm}\end{array}$ & $\mathrm{w}_{\mathrm{n}}(\%)$ \\
\hline BH1 & UD1 & $2.50-3.00$ & 1.23 & 40.65 & 23.57 & 55.44 & 38.86 \\
\hline BH6 & UD1 & $1.00-1.50$ & 1.14 & 73.80 & 46.42 & 97.04 & 48.43 \\
\hline
\end{tabular}

Tabel 2. Nilai tekanan pengembangan metode empiris dan hasil pengetesan laboratorium Kawasan Jawa Barat 1

\begin{tabular}{cccccc}
\hline \multirow{2}{*}{ Bor No. } & \multirow{2}{*}{ Sample No. } & Sample & \multicolumn{3}{c}{ Swelling Pressure $\left(\mathrm{t} / \mathrm{m}^{2}\right)$} \\
\cline { 4 - 6 } & & Depth $(\mathrm{m})$ & Nayak \& Christensen & Kormonik \& david & Laboratorium \\
\hline BH1 & UD1 & $2.50-3.00$ & 4.44 & 0.31 & 0.25 \\
\hline BH6 & UD1 & $1.00-1.50$ & 10.11 & 0.72 & 1.00 \\
\hline
\end{tabular}

Tabel 3. Parameter tanah Kawasan Jawa Barat 2

\begin{tabular}{cccccccc}
\hline \multirow{3}{*}{ Bor No. } & Sample No. & Depth $(\mathrm{m})$ & $\begin{array}{c}\text { Dry Density } \\
\left(\mathrm{gr} / \mathrm{cm}^{3}\right)\end{array}$ & LL (\%) & PI (\%) & $\begin{array}{c}\text { \% finer } \\
<0.002 \mathrm{~mm}\end{array}$ & Wi (\%) \\
\hline \multirow{3}{*}{ BH1 } & UD1 & $1.00-1.50$ & 1.00 & 93.15 & 53.99 & 96.74 & 58.24 \\
\cline { 2 - 7 } & UD2 & $3.00-3.50$ & 1.06 & 71.00 & 30.33 & 98.33 & 54.11 \\
\cline { 2 - 7 } & UD3 & $5.00-5.50$ & 1.10 & 100.85 & 68.70 & 98.87 & 48.27 \\
\hline \multirow{3}{*}{ BH2 } & UD1 & $1.50-2.00$ & 1.05 & 93.65 & 57.27 & 96.16 & 54.88 \\
\cline { 2 - 7 } & UD2 & $3.50-4.00$ & 0.95 & 99.75 & 41.86 & 93.08 & 59.15 \\
\hline \multirow{2}{*}{ BH3 } & UD3 & $5.50-6.00$ & 1.22 & 89.90 & 59.08 & 92.62 & 43.07 \\
\cline { 2 - 7 } & UD1 & $2.00-2.50$ & 1.05 & 89.85 & 52.67 & 95.80 & 53.18 \\
\cline { 2 - 7 } & UD2 & $4.00-4.50$ & 1.10 & 92.40 & 53.73 & 94.48 & 44.58 \\
\hline
\end{tabular}

Tabel 4. Nilai tekanan pengembangan metode empiris Kawasan Jawa Barat 2

\begin{tabular}{cccccc}
\hline \multirow{2}{*}{ Bor No. } & \multirow{2}{*}{ Sample No. } & \multirow{2}{*}{ Depth $(\mathrm{m})$} & \multicolumn{3}{c}{ Swelling Pressure $\left(\mathrm{t} / \mathrm{m}^{2}\right)$} \\
\cline { 3 - 6 } & & & Nayak \& Christensen & Kormonik \& david & Laboratorium \\
\hline \multirow{3}{*}{ BH1 } & UD1 & $1.00-1.50$ & 8.72 & 0.17 & N/A \\
\cline { 2 - 6 } & UD2 & $3.00-3.50$ & 6.47 & 0.08 & N/A \\
\cline { 2 - 6 } & UD3 & $5.00-5.50$ & 14.72 & 0.47 & N/A \\
\hline \multirow{3}{*}{ BH2 } & UD1 & $1.50-2.00$ & 9.86 & 0.22 & N/A \\
\cline { 2 - 6 } & UD2 & $3.50-4.00$ & 6.76 & 0.23 & N/A \\
\hline \multirow{2}{*}{ BH3 } & UD3 & $5.50-6.00$ & 13.89 & 0.38 & N/A \\
\cline { 2 - 6 } & UD1 & $2.00-2.50$ & 9.59 & 0.39 & N/A \\
\cline { 2 - 6 } & UD3 & $6.00-4.50$ & 12.47 & 0.57 & N/A \\
\hline
\end{tabular}

Catatan: $\mathrm{N} / \mathrm{A}=$ data Laboratorium tidak tersedia 


\section{Kapasitas Dukung Micropile}

Berikut merupakan spesifikasi micropile yang digunakan untuk analisis kapasitas micropile yaitu

1. $\mathrm{f}_{\mathrm{c}}{ }_{\mathrm{C}}$

2. $\mathrm{f}_{\mathrm{y}}$ casing

3. $\mathrm{f}_{\mathrm{y}}$ bar

4. Diameter luar (OD)

5. $\mathrm{t}_{\mathrm{w}}$

6. $\mathrm{D}_{\text {tulangan }}$

7. Diameter bor

$$
\begin{array}{ll}
=25 & \mathrm{MPa} \\
=235 & \mathrm{MPa} \\
=400 & \mathrm{MPa} \\
=165.2 & \mathrm{~mm} \\
=6 & \mathrm{~mm} \\
=13 & \mathrm{~mm} \\
=200 & \mathrm{~mm}
\end{array}
$$

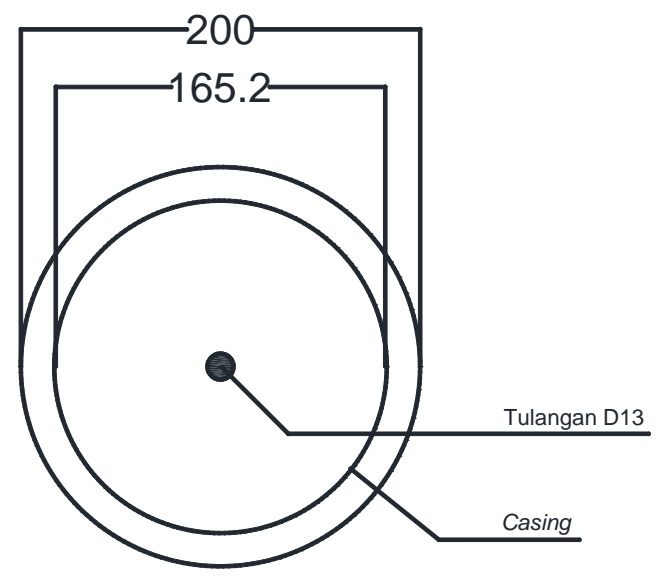

Gambar 1. Detail micropile

Berdasarkan Spesifikasi yang dipakai tersebut setelah dilakukan analisis data, didapati nilai kapasitas dukung vertikal sebagai berikut. Pada bagian cased length micropile didapati bahwa nilai $\mathrm{P}_{\mathrm{c} \text {-allowable }}$ adalah sebesar 52.91 ton dan $\mathrm{P}_{\mathrm{t} \text {-allowable }}$ adalah sebesar 40.50 ton. Pada bagian uncased length micropile didapati bahwa nilai $\mathrm{P}_{\mathrm{c}-\text { allowable }}$ adalah sebesar 33.91 ton dan $\mathrm{P}_{\mathrm{t}-\text { allowable }}$ adalah sebesar 2.92 ton.

\section{Kebutuhan Micropile}

Berdasarkan hasil analisis dan perhitungan data, didapati jumlah kebutuhan micropile yang diperlukan untuk meminimalkan heaving pada tanah ekspansif berdasarkan tekanan pengembangan yang terjadi. Analisis area pengembangan dilakukan pada area berukuran $1 \mathrm{x} 1 \mathrm{~m}^{2}$. Kebutuhan penggunaan micropile disajikan pada tabel 5.

Tabel 5. Kebutuhan jumlah micropile

\begin{tabular}{ccc}
\hline \multirow{2}{*}{$\begin{array}{c}\text { Gaya Pengembangan } \\
\text { (Ton) }\end{array}$} & Kawasan Jawa Barat 1 & Kawasan Jawa Barat 2 \\
\cline { 2 - 3 } & 1 & 12 \\
\hline Kebutuhan (buah) & $1 / 2.92=0.34$ & 12 / 40.5 = 0.01 \\
\hline Pemakaian (buah) & 1 & 1
\end{tabular}

\section{KESIMPULAN}

Dari hasil analisis yang dilakukan, dapat disimpulkan beberapa hal berikut ini: 
1. Berdasarkan hasil pengolahan data, didapati bahwa tekanan pengembangan tanah ekspansif Kawasan Jawa Barat 2 lebih besar jika dibandingkan dengan Kawasan Jawa Barat 1. Hal ini dikarenakan nilai batas cair (LL), indeks plastisitas (PI), dan persen fraksi ukuran butir < 0.002 mm Kawasan Jawa Barat 2 lebih besar dibandingkan dengan Kawasan Jawa Barat 1.

2. Berdasarkan pengolahan data, didapati bahwa kapasitas tarik pada micropile efektif untuk meminimalkan heaving pada tanah ekspansif. Pada Kawasan Jawa Barat 1, kapasitas tarik sebesar 2.92 Ton (Uncased Length). Pada Kawasan Jawa Barat 2, kapasitas tarik sebesar 40.5 Ton (Cased Length).

\section{DAFTAR PUSTAKA}

Bella, Rosmiyati A., dkk.(2015). Identifikasi Kerusakan Konstruksi Akibat Potensi Pengembangan Tanah Lempung Eekspansif di Desa Oebelo. Jurnal Teknik Sipil, Vol. 4. No. 2, 195-208.

Federal Highway Administration.(2005). Micropile Design and Construction. Washington, D.C.

Hardiyatmo, Hary Christady.(2014). Tanah Ekspansif Permasalahan dan Penanganan. Gajah Mada University Press, Yogyakarta.

Putra, Made Dwika H. (2017). Pengaruh Perbaikan Tanah Lempung Ekspansif Dengan Metode Deep Soil Mixing pada Berbagai Kadar Air Lapangan Tanah Asli Terhadap Nilai CBR dan Pengembangan. Skripsi, Universitas Brawijaya.

Tu, Hongyu.(2016). Prediction of the Variation of Swelling Pressure and 1-D Heave of Expansive Soils with Respect to Suction. Tesis. University of Ottawa. 
